Artigo / Article

\title{
Avaliação da importância da coloração de Perls na rotina de mielogramas de pacientes com anemia associada a uma ou mais citopenias em sangue periférico
}

\author{
Evaluation of the importance of Perls stain in the routine testing of myelograms of patients with \\ anemia associated with one or more peripheral blood cytopenias
}

\author{
Nydia S. Bacal \\ João C. C. Guerral \\ Robson J. Lázaro ${ }^{2}$ \\ Márcia R. Ioshida \\ Irina Y. Takihi ${ }^{3}$ \\ Luiz G. M. Rosenfeld ${ }^{4}$ \\ Regina A. Kuabara \\ Celso C. C. Guerra ${ }^{6}$
}

\begin{abstract}
As síndromes mielodisplásicas (SMD) são um grupo heterogêneo de doenças malignas das células-tronco hematopoéticas, classificadas segundo a Organização Mundial da Saúde (OMS) em: anemia refratária, anemia refratária com sideroblastos em anel, citopenia refratária com displasia de multilinhagens, anemia refratária com excesso de blastos, síndrome mielodisplásica inclassificável e sindrome mielodisplásica associada com anormalidade isolada do cromossomo $5 q(\mathrm{del})$. Na anemia refratária com sideroblastos em anel observam-se hiperplasia e displasia eritróide com presença de $15 \%$ ou mais de sideroblastos em anel. Utilizamos neste estudo a coloração de Perls em esfregaços de medula óssea de pacientes com idade superior a 40 anos e que apresentavam uma ou mais citopenias no sangue periférico associada a anemia. Por tratar-se de técnica de manejo fácil e ágil sugerimos seu emprego em esfregaços de aspirado de medula óssea de pacientes que apresentem os achados laboratoriais acima, pois, dentre os casos analisados 18,7\% apresentavam mais que 10 grânulos sideróticos circundando a terça parte ou mais do núcleo do precursor eritróide (sideroblasto em anel), sugerindo ao hematologista um possivel diagnóstico de Síndrome Mielodisplásica com Sideroblastos em Anel (SMD-ARSA). Importante relatar que a grande maioria destes casos com aumento de sideroblastos em anel não foi encaminhada ao nosso serviço, com suspeita de SMD, e em somente um caso foi solicitada a realização da coloração de Perls. Rev. bras. hematol. hemoter. 2005;27(2):91-93.
\end{abstract}

Palavras-chave: Medula óssea; sindrome mielodisplásica; anemia refratária; coloração de Perls; ferro medular.

\section{Introdução}

Segundo a Organização Mundial da Saúde (OMS), a anemia refratária com sideroblastos em anel (ARSA) é uma síndrome caracterizada por anemia em que $15 \%$ ou mais dos precursores eritróides no aspirado de medula óssea, são sideroblastos em anel. O sideroblasto em anel é definido como um precursor eritróide em que a terça parte, ou mais, do núcleo, é rodeado por dez ou mais grânulos sideróticos ou células normoblásticas com cinco ou mais grânulos formando anel parcial ou completo ao redor do núcleo, demonstrados pela coloração de Perls. ${ }^{1-5}$

\footnotetext{
${ }^{I}$ Médica hematologista e patologista clínica do Centro de Hematologia de São Paulo e do Depto. de Patologia Clínica do Hospital Albert Einstein. ${ }^{2}$ Farmacêutico-bioquímico do Centro de Hematologia de São Paulo.

${ }^{3}$ Biomédica do Centro de Hematologia de São Paulo.

${ }^{4}$ Médico hematologista e patologista clínico do Centro de Hematologia de São Paulo e do Diagnósticos da América.

${ }^{5}$ Física do Centro de Hematologia de São Paulo.

${ }^{6}$ Médico hematologista e patologista clínico do Centro de Hematologia de São Paulo e Livre-Docente em Hematologia pela Unifesp.
}

Instituição: Centro de Hematologia de São Paulo.

Correspondência para: Nydia Strachman Bacal

Centro de Hematologia de São Paulo

Av. Brigadeiro Luiz Antonio, 2533 - Jd. Paulista

01401-000 - São Paulo-SP

Tel.: (11) 33726611 -Fax: (11) 32842575 -E-mail: hemato@chsp.org.br 
Em 1947 foram descritos inicialmente grânulos ferropositivos nos eritroblastos, incluindo sua distribuição perinuclear. Primeiro eles foram associados à anemia sideroblástica adquirida, por Bjorkman, ${ }^{6}$ e subseqüentemente descobriu-se que era um achado constante em anemia microcítica hereditária, assim como na anemia responsiva à piridoxina. ${ }^{7,8}$ Os estudos com microscópio eletrônico de Caroli et al revelaram que os grânulos sideróticos representam os únicos depósitos de ferro na mitocôndria dos eritroblastos. ${ }^{9}$ Logo, numerosos pacientes com anemia refratária de causa desconhecida, hereditária ou adquirida, exibiam sideroblastos em anel ao exame de medula óssea e foram a base de um Simpósio em 1965, quando foi adotado o termo anemia sideroblástica. Causas secundárias de sideroblastos em anel, como drogas usadas no tratamento de tuberculose e alcoolismo, devem ser excluídas. Em geral, a proporção de sideroblastos em anel e outros tipos de dispoese são mais proeminentes na ARSA, quando comparadas a processos não neoplásicos. ${ }^{10} \mathrm{O}$ objetivo deste trabalho é demonstrar a importância da inclusão da coloração de Perls na rotina de mielogramas de pacientes com anemia associada a uma ou mais citopenias em sangue periférico.

\section{Casuística e Métodos}

No período de novembro de 2002 a abril de 2004 foram realizados 2.262 mielogramas no laboratório clínico do Centro de Hematologia de São Paulo. Destes aspirados de medula óssea, 893 (39,5\%) foram solicitados a pacientes com idade igual ou superior a 40 anos e com, pelo menos, uma citopenia no sangue periférico. Em 107 amostras (12\%), a citopenia apresentava-se em conjunto com anemia, sendo que, nestas, foi realizada coloração de Perls, segundo técnica recomendada. ${ }^{7}$ Foram consideradas citopenias a presença de hemoglobina inferior a $12,5 \mathrm{~g} / \mathrm{dL}$ para mulheres e $14,3 \mathrm{~g} / \mathrm{dL}$ para homens, contagem global de leucócitos inferior a $3.500 / \mathrm{mm}^{3}$ e contagem de plaquetas inferior a $130.000 / \mathrm{mm}^{3}$. Não fizeram parte do presente estudo esfregaços de aspirado de medula óssea de pacientes encaminhados para controle de doenças oncohematológicas. Todas as amostras foram analisadas citomorfologicamente em esfregaços corados pelo método pancromático de Romanowski. Na avaliação da coloração de Perls, foram quantificados o número de grânulos existentes nos precursores eritróides para diferenciação de sideroblastos em anel, que possuem núcleo circundado com dez ou mais grânulos sideróticos, conforme visualizados nas figuras 1 e 2 .

\section{Resultados}

Das 107 amostras avaliadas, 20 amostras (18,7\%) apresentaram sideroblastos em anel. Na análise morfológica destas 20 amostras observou-se que todas apresentavam hiperplasia da linhagem eritróide e displasia de uma única linhagem ou associada a displasias de multilinhagens conforme
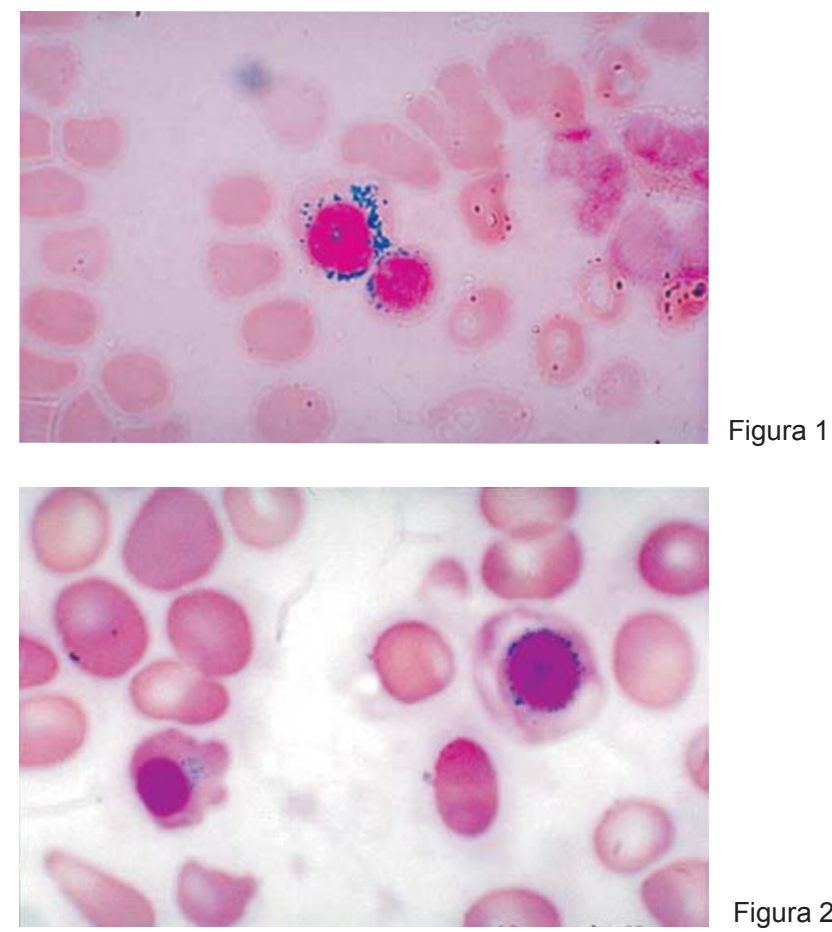

Figura 2

\begin{tabular}{cc} 
Tabela 1 \\
\hline $\begin{array}{c}\text { Número de } \\
\text { amostras }\end{array}$ & $\begin{array}{c}\text { Linhagens que apresentaram } \\
\text { displasias }\end{array}$ \\
\hline 9 & $\begin{array}{l}\text { Linhagem eritróide e granulocítica } \\
\text { Linhagem eritróide } \\
\text { Linhagem eritróide, granulocítica e } \\
\text { megacariocítica }\end{array}$
\end{tabular}

\begin{tabular}{cc}
\multicolumn{2}{c}{ Tabela 2 } \\
\hline Décadas & Percentual \\
\hline 40 a 50 anos & $10 \%$ \\
51 a 60 anos & $5 \%$ \\
61 a 70 anos & $25 \%$ \\
71 a 80 anos & $50 \%$ \\
81 a 90 anos & $10 \%$ \\
\hline
\end{tabular}

demonstrado na tabela 1 . A idade dos pacientes variou de 43 a 89 anos, com média de 77 anos e a incidência por década de vida está demonstrada na tabela 2 .

\section{Discussão}

Há mais de seis décadas que existem referências esparsas na literatura a várias entidades relacionadas a Síndromes Mielodisplásicas (SMD) sob denominações como anemia refratária (1941), pré-leucemia (1953), anemia refratária com sideroblastos em anel (1956) e leucemia mielomonocítica. ${ }^{10}$

As SMD são um grupo heterogêneo de doenças malignas das células-tronco hematopoéticas, caracterizadas 
pela produção de células ineficientes e displásicas no sangue periférico, que apresentam um risco variável de transformação em leucemia aguda. A displasia pode ser acompanhada de um aumento de mieloblastos mas em número inferior a $20 \% .1,5$

O grupo cooperativo Franco-Americano-Britânico (FAB), em 1982, distingue cinco subtipos morfológicos de SMD de acordo com os achados no sangue periférico e medula óssea denominados anemia refratária (AR), anemia refratária com sideroblastos em anel (ARSA), anemia refratária com excesso de blastos (AREB), anemia refratária com excesso de blastos em transformação (AREB-t) e leucemia mielomonocítica crônica (LMMC). A presença de mais de 15\% de sideroblastos em anel na medula óssea, acompanhados pelo aumento nos mieloblastos (acima de 5\%) ou monocitose, é considerada como AREB, ou LMMC, respectivamente. ${ }^{3,4,5}$

A classificação mais atualizada segue o comitê da OMS: anemia refratária, anemia refratária com sideroblastos em anel, citopenia refratária com displasia de multilinhagem, anemia refratária com excesso de blastos, síndrome mielodisplásica inclassificável, síndrome mielodisplásica associada com anormalidade isolada do cromossomo $5 \mathrm{q}(\mathrm{del})$.

A ARSA ocorre predominantemente em adultos idosos, com média de idade em torno de 70 anos, mais freqüentemente em homens do que mulheres e correspondem a $10 \%$ a $20 \%$ dos casos de SMD. ${ }^{1}$

$\mathrm{Na}$ medula óssea observa-se hiperplasia eritróide. A displasia é restrita a esta linhagem, com a presença de $15 \%$ ou mais de sideroblastos em anel. Podem haver outras evidências de diseritropoese, como lobulação nuclear e características megaloblastóides. Os mieloblastos são menos que $5 \%$ na medula e não estão presentes no sangue periférico. ${ }^{1,11,12,13}$ Anormalidades clonais cromossômicas são vistas em menos de $10 \%$ dos casos. ${ }^{1}$

$\mathrm{O}$ aumento de sideroblastos em anel acima de $15 \%$ do total de precursores eritróides, segundo a OMS, em conjunto com hiperplasia e displasia das linhagens, associado a outros dados laboratoriais, sugere o diagnóstico de Síndrome Mielodisplásica com Sideroblastos em Anel (SMD-ARSA).

\section{Conclusão}

A incorporação da coloração de ferro medular mostrouse importante no auxílio diagnóstico e sugere-se utilizar na rotina da liberação dos mielogramas, em pacientes com anemia associada a citopenias em sangue periférico, independente da solicitação clínica, levando-se em conta que somente um caso (5\%) nos foi enviado com suspeita de SMD e 12 casos $(60 \%)$ não tinham solicitação médica.

\section{Abstract}

Myelodisplastic syndromes are a heterogeneous group of malignant haematopoietic stem cells. They are classified by the World Health
Organization as refractory anemia, refractory anemia with ringed sideroblasts, refractory cytopenia with multilineage displasia, refractory anemia with excess of blast cells, unclassified myelodisplastic syndrome and myelodisplastic syndrome associated with a $5 q$ chromosomal delection. Refractory anemia with ringed sideroblasts is defined by red blood cell hyperplasia and dysplasia with $15 \%$ or more of ringed sideroblasts. We studied bone marrow aspirates using Perls' stain with blood smears from over 40-yearold patients that had one or more cytopenias in their peripheral blood associated with anemia. A total of $18.7 \%$ of patients had ringed sideroblasts leading to a possible diagnosis of refractory anemia with ringed sideroblasts, one of the myelodisplastic syndromes. Most of those cases were refered to our service without clinical suspicion of myelodisplastic syndrome and in only one case Perls' stain was requested. Perls' stain is easily performed and the results are fast and so we suggest that it should be routinely used in all cases of possible myelodisplastic syndrome. Rev. bras. hematol. hemoter. 2005;27(2):91-93.

Key words: Bone marrow; myelodisplastic syndromes; refractory anemia; Perls' stain; blood iron.

\section{Referências Bibliográficas}

1. Brunning RD, Bennett JM, Flandrin G, et al.World Health Organization Classification of Tumours: Pathology and Genetics of Tumours of Haematopoietic and Lymphoid Tissues. Lyon: IARC Press, 2001. Edited by Jaffe, E S; Harris, N L; Stein, H; Vardiman, J W -Capítulo 3, p 63 e 69.

2. Lambertenghi-Deliliers G, Annaloro C, Oriani A, et al. Prognostic relevance of histological findings on bone marrow biopsy in myelodysplastic syndromes. Ann Hematol 1993 Feb;66(2):85-91.

3. Foucar K. Bone Marrow Pathology. 2nd Edition, 2001 - American Society for Clinical Pathology. Press. p 238-239.

4. Naeim F. Atlas of Bone Marrow and Blood Pathology. 1st Edition, 2001 - W.B. Saunders Company - p 35.

5. Deiss, A. In Lee GR, Bithell TC, Foerster J, et al. Hematologia Clínica. 9th ed. 1998. Ed. Manole. $1^{a}$ edição brasileira p 2.147-49.

6. Bjorkman SE. Chhronic Refratory Anemia with sideroblastic bone marrow: a study of four cases. Blood 1956;11:250-9.

7. Dacie JV. Practical Haematology - 7th Ed. 1991- Churchill Livingstone, p 117

8. Dacie JV, Mollin DL. Siderocytes, sideroblasts and sideroblastic anaemia. Acta Medica Scandinavica 1966 - 179 suppl, 445. p 237

9. Caroli J, Bernard J, Bessis M, et al. Hemochromatose avec anemie hypochrome et absence d'hemoglobine anormale. Presse Med 1957; 65:1991-1992.

10. Zago MA, Falcão RP, Pasquini R. Hematologia - Fundamentos e Prática. 2001 - Editora Atheneu, p 522

11. Sun T. Flow cytometric analysis of hematologic neoplasms. A color atlas \& text. 2nd Ed. 2002 - Lippincott Willians \& Wilkins, p 261

12. Kouides PA, Bennett JM. Morphology and classification of the myelodysplastic syndromes and their pathologic variants. Semin Hematol 1996;33:95-110

13. Hoffbrand AV, Pettit JE. Clinical Haematology. 2nd Edition. 1994, Edited by Mosby- Wolfe p 205

Avaliação: Editor e dois revisores externos.

Conflito de interesse: não declarado

Recebido: 21/12/2004

Aceito após modificações: 16/06/2005 